\title{
Primary ectopic breast cancer of the vulva, treated with local excision of the vulva and sentinel lymph node biopsy: a case report
}

\author{
Takayuki Ishigaki (D), Yasuo Toriumi, Ryouko Nosaka, Rei Kudou, Yoshimi Imawari, Makiko Kamio, Hiroko Nogi, \\ Hisashi Shioya and Hiroshi Takeyama
}

\begin{abstract}
Primary breast cancer fairly infrequently occurs in ectopic breast tissue, and primary ectopic breast cancer of the vulva is particularly rare. Only 26 cases have been published in the English-language literature, and there has been no report of primary breast carcinoma of the vulva in Japan. We report a rare case of primary ectopic breast cancer of the vulva that was treated with local excision of the vulva and sentinel lymph node biopsy (SLNB). The patient was a 72-year-old woman who had noticed a right vulvar tumor 10 years earlier. The tumor was excised by the Department of Plastic Surgery of our hospital. The histology of the vulvar tumor revealed an invasive ductal carcinoma of the breast, and immunohistochemical staining of the vulvar specimen showed the tumor cells to be 100\% estrogen-receptor-positive and 100\% progesterone-receptor-positive. All margins of resection were positive for neoplastic involvement. An additional local excision of the vulva and right inguinal SLNB were performed in our department. The intraoperative frozen section was negative for metastasis, and lymph node dissection was not performed. The final pathology was negative for residual disease, and a partially normal ductal component was present. Adjuvant hormonal therapy with an aromatase inhibitor was indicated post-operatively. The patient was asymptomatic and free of detectable disease at a 6-month follow-up. Due to the rarity of this diagnosis, there are no established guidelines for treatment. Although cases in which SLNB was performed are rare, we consider SLNB to be an effective alternative to inguinal node dissection for ectopic primary breast cancer of the vulva.
\end{abstract}

Keywords: Ectopic breast cancer, Breast cancer of the vulva, Sentinel lymph node biopsy

\section{Background}

Ectopic mammary tissue may occur anywhere along the milk line, which extends bilaterally from the axilla to the groin. The frequency of ectopic breast tissue in females is 1 to $6 \%$, and it is relatively common in the axilla or on the thorax but rare in the vulva [1]. Primary breast cancer fairly infrequently occurs in the ectopic breast tissue, and ectopic primary breast cancer of the vulva is particularly rare. Only 26 cases have been published in the English-language literature. There are no guidelines for treating breast cancer of the vulva because of its rarity. We report a rare case of primary ectopic breast cancer of the vulva that was treated with local excision of the vulva and sentinel lymph node biopsy (SLNB).

\footnotetext{
* Correspondence: tippdwr@yahoo.co.jp

Department of Breast and Endocrine Surgery, The Jikei University School of Medicine, 3-25-8, Nishi-shinbashi, Minato-ku, Tokyo 105-8461, Japan
}

\section{Case presentation}

The patient was a 72-year-old woman (gravida 0 and para 0), with no history of malignancy or breast disease and no family history of carcinoma. She had been aware of a left third finger tumor for 20 years and a right vulvar tumor for 10 years. These tumors were excised at the Department of Plastic Surgery of our hospital. The histology of the finger tumor revealed a schwannoma, and the vulvar tumor revealed an invasive ductal carcinoma of the breast (see Fig. 1). Immunohistochemical staining of the vulvar specimen showed the tumor cells to be $100 \%$ estrogen-receptor-positive, $100 \%$ progesterone-receptorpositive, human epidermal growth factor 2-negative, and gross cystic disease fluid protein 15 (GCDFP-15)-positive (see Fig. 2). All margins of resection were positive for neoplastic involvement. The patient was referred to our department for further assessment and treatment. There 


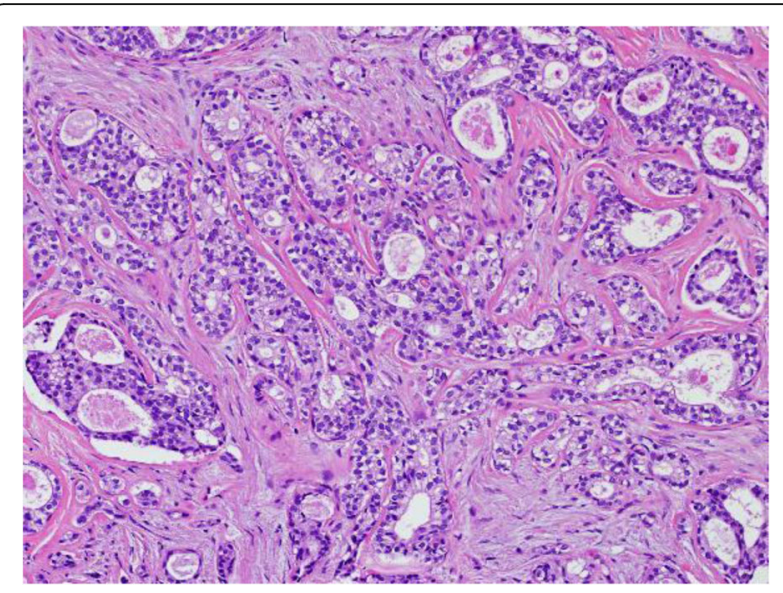

Fig. 1 Histopathological findings of the resected specimen (hematoxylin-eosin stain, $\times 200$ ). Invasion of the stroma by ductal adenocarcinoma

was a $20-\mathrm{mm}$ operation scar in the upper right direction of the right labia majus. The results of the breast examination and mammary imaging (mammography and ultrasound) were negative for primary breast tumors. The chest-abdomen-pelvic CT scan, bone scintigraphy, and inguinal ultrasound showed no secondary neoplastic lesions. The diagnosis of a primary ectopic breast cancer of the vulva was established.

Additional local excision of the vulva and SLNB were performed. We used preoperative ${ }^{99 \mathrm{~m}}$ Tc-phytic acid lymphoscintigraphy and indocyanine green (ICG) lymph node localization in the SLNB. ${ }^{99 \mathrm{~m}}$ Tc-phytic acid was injected into the subcutaneous tissue near the previous right surgical site on the day before surgery. Lymphoscintigraphy showed hot areas at the right inguinal lymph node and right obturator lymph node (see Fig. 3). The inguinal lymph node was determined to be a sentinel

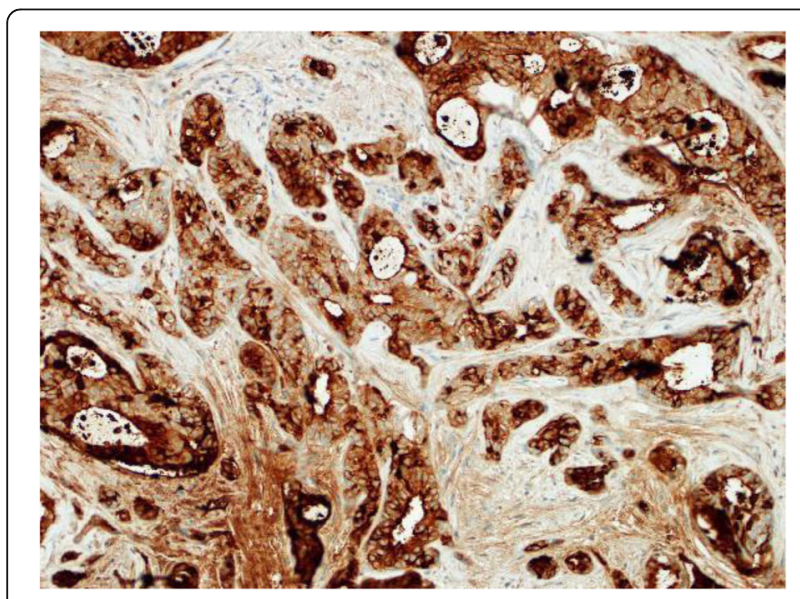

Fig. 2 Histopathological findings of the resected specimen (GCDFP-15 stain, $\times 200$ ). Positive for GCDFP-15 expression

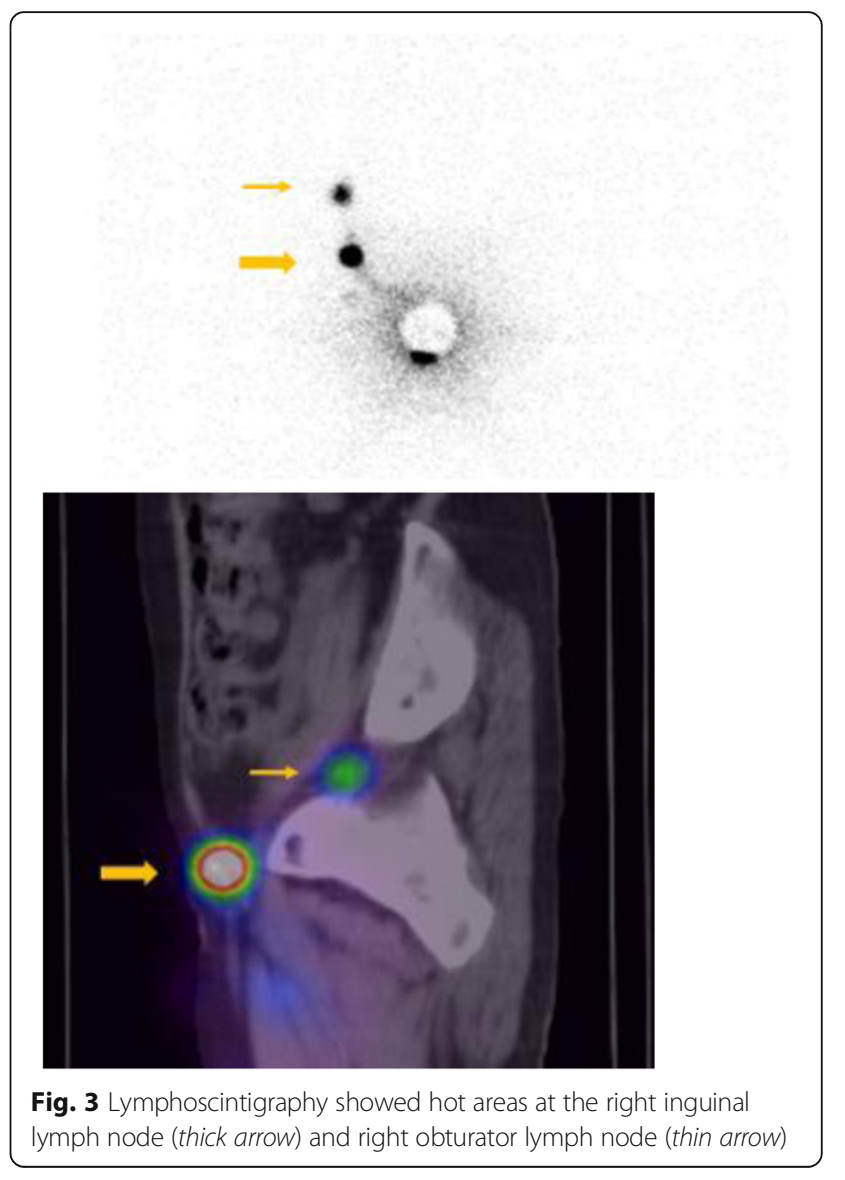

lymph node based on the image. In the operation, ICG was also injected into the same site near the previous operative scar. A right inguinal incision was created, and the $\gamma$-probe was used to identify the hot area. A hot, green sentinel lymph node was identified and excised. Then, an additional local excision of the vulva with $10-\mathrm{mm}$ margins from the previous operative scar was performed. The intraoperative frozen section was negative for sentinel lymph metastasis, and a lymph node dissection was not performed. The final pathology was negative for residual disease, and a partially normal ductal component was present (see Fig. 4). Adjuvant hormonal therapy with an aromatase inhibitor was indicated post-operatively. The patient was asymptomatic and free of detectable disease at a 6-month follow-up.

\section{Discussion}

Ectopic breast tissue can occur anywhere along the primitive embryonic milk lines and may develop benign and malignant pathologic processes similar to those seen in normally located breast tissue, such as fibroadenoma, intraductal papilloma, fibrocystic disease, lactating adenoma, hidradenoma papilliferum, and carcinoma $[2,3]$. Any of the various histological subtypes of breast cancer may occur in the vulva, including infiltrating ductal, 


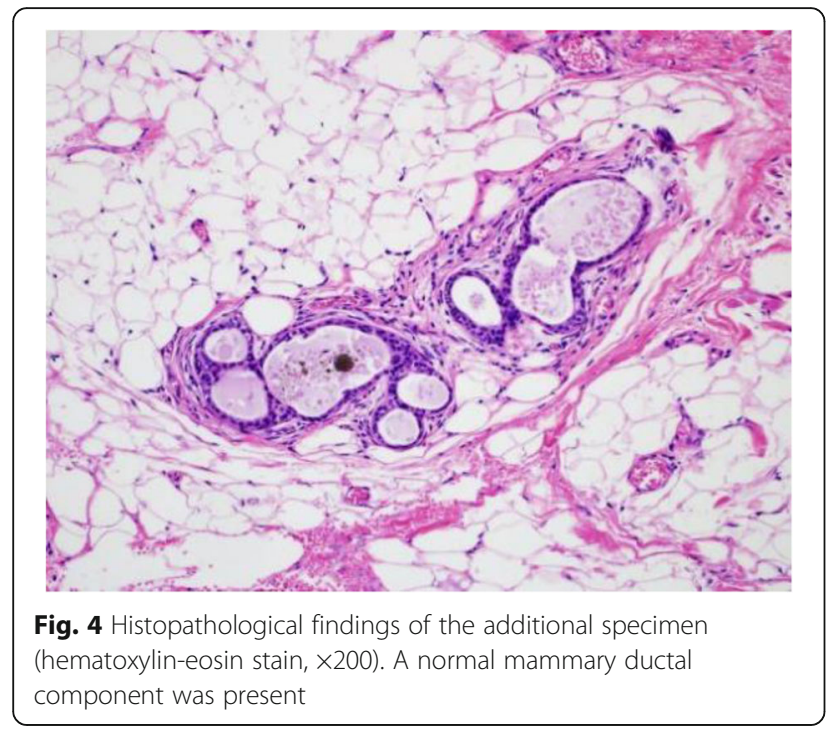

lobular, mucinous, mixed ductal, and lobular carcinomas $[3,4]$. There have been 26 cases of primary ectopic breast carcinoma of the vulva described in the Englishlanguage literature since the first report by Green in 1935 (see Table 1). Our case is the first reported case of primary breast carcinoma of the vulva in Japan and the 27th case reported worldwide.

A diagnosis of primary ectopic breast cancer located in the vulva has generally been based on histopathologic patterns. Histology criteria for the diagnosis include (1) a morphology consistent with breast carcinoma; (2) positive estrogen and/or progesterone-receptor expression on immunohistochemical staining; (3) immunostaining positive for additional common breast cancer-associated markers including carcinoembryonic antigen, CK7, and mammoglobin; and (4) presence of a non-neoplastic breast tissue or carcinoma in situ component [5]. The GCDFP-15 used in our case is also a specific marker of breast cancer [6]. In addition, it is necessary to exclude

Table 1 The characteristics of primary ectopic breast carcinoma of the vulva

\begin{tabular}{|c|c|c|c|c|c|c|c|c|c|c|c|c|}
\hline \multirow{2}{*}{$\begin{array}{l}\text { Ref. } \\
\text { Greene [12] }\end{array}$} & \multirow{2}{*}{$\begin{array}{l}\text { Year } \\
1935\end{array}$} & \multirow{2}{*}{$\begin{array}{l}\text { Age } \\
59\end{array}$} & \multicolumn{2}{|c|}{ Size $(\mathrm{cm})$ operation } & \multirow{2}{*}{$\begin{array}{l}\text { Adjuvant therapy } \\
\text { None }\end{array}$} & \multirow{2}{*}{$\begin{array}{l}\text { Histology } \\
\text { Adenocarcinoma }\end{array}$} & \multirow{2}{*}{$\begin{array}{l}\text { ER } \\
*\end{array}$} & \multirow{2}{*}{$\begin{array}{l}\text { PR } \\
*\end{array}$} & \multirow{2}{*}{$\begin{array}{l}\text { Her2 } \\
*\end{array}$} & \multirow{2}{*}{$\begin{array}{l}\text { LN } \\
*\end{array}$} & \multirow{2}{*}{$\begin{array}{l}\text { Status } \\
\text { Dead }\end{array}$} & \multirow{2}{*}{$\begin{array}{l}\begin{array}{l}\text { Follow-up } \\
\text { (months) }\end{array} \\
1\end{array}$} \\
\hline & & & 20 & None & & & & & & & & \\
\hline Hendrix [13] & 1956 & 58 & 3 & Vulvectomy & None & Adenocarcinoma & * & * & * & * & Dead & 4 \\
\hline Guerry [14] & 1976 & 62 & 1.5 & Partial & None & Ductal carcinoma & * & * & $*$ & * & Dead & 24 \\
\hline Cho [15] & 1985 & 70 & 4 & Hemi-vulvectomy + LND & Tamoxifen & Adenocarcinoma & $(+)$ & $(+)$ & * & $2 / 9$ & DF & 24 \\
\hline Simon [16] & 1988 & 60 & 2 & Vulvectomy + LND1 & $\mathrm{CT}+$ tamoxifen & Adenocarcinoma & $(+)$ & $(+)$ & * & $3 / 11$ & Dead & 27 \\
\hline Rose [17] & 1990 & 68 & 3.5 & Vulvectomy & RT + tamoxifen & Ductal carcinoma & $(+)$ & $(-)$ & * & $1 / 15$ & $*$ & $*$ \\
\hline Bonito [18] & 1992 & 46 & 1.5 & Vulvectomy + LND & None & * & * & * & * & $11 / 13$ & DF & 4 \\
\hline Bailey [19] & 1993 & 65 & 3 & Vulvectomy + LND & Tamoxifen & Ductal carcinoma & $(+)$ & $(+)$ & * & $2 / 20$ & DF & 12 \\
\hline Levin [20] & 1994 & 62 & 2.5 & Partial + LND & Tamoxifen & Adenocarcinoma & $(+)$ & $(-)$ & $(+)$ & $4 / 11$ & DF & 24 \\
\hline Kennedy [21] & 1997 & 71 & 5 & Vulvectomy + LND & $C T+R T$ & * & $(-)$ & $(-)$ & * & 9/9 & DF & 15 \\
\hline Irvin [22] & 1998 & 64 & 3 & Partial + LND & $\mathrm{CT}+\mathrm{RT}-\mathrm{F}$ tamoxifen & Adenocarcinoma & $(+)$ & $(+)$ & * & $1 / 14$ & DF & 4 \\
\hline Gorisek [23] & 2000 & 81 & 3 & Partial & Tamoxifen & Adenocarcinoma & $(+)$ & $(+)$ & * & & DF & 19 \\
\hline Neumann [24] & 2000 & 60 & 3 & Hemi-vulvectomy + LND & $\mathrm{CT}+\mathrm{RT}+$ tamoxifen & ILC & $(+)$ & $(+)$ & * & $21 / 21$ & DF & 20 \\
\hline Piura [25] & 2002 & 69 & 3 & Vulvectomy + LND & $C T+$ tamoxifen & Adenocarcinoma & $(+)$ & $(+)$ & $*$ & $7 / 15$ & DF & 14 \\
\hline Chung [26] & 2002 & 47 & 2 & Vulvectomy & None & Mucinous & $(+)$ & $(+)$ & $(-)$ & * & DF & 36 \\
\hline Yin [27] & 2003 & 84 & 5 & Partial + LND & None & Mucinous & $(+)$ & $(+)$ & $(-)$ & $1 / 11$ & DF & 9 \\
\hline Lopes [28] & 2006 & 44 & 2 & Partial + LND & $C T+$ tamoxifen & Mucinous & $(+)$ & * & $(-)$ & $2 / 13$ & * & $*$ \\
\hline Fracchioli [29] & 2006 & 57 & 1 & Vulvectomy + LND & $C T+$ tamoxifen & Adenocarcinoma & $(-)$ & * & * & $7 / 7$ & $\operatorname{Rec}$ & 36 \\
\hline North [4] & 2006 & 49 & 1.5 & Partial + LND & $C T+$ tamoxifen & Ductal carcinoma & $(+)$ & $(+)$ & $(-)$ & $5 / 7$ & * & * \\
\hline Martinez [10] & 2007 & 49 & 3.5 & Partial + SLNB —LND & Tamoxifen & Ductal carcinoma & $(+)$ & $(+)$ & $*$ & $0 / 14$ & $*$ & * \\
\hline Naseer [30] & 2011 & 57 & 1.5 & Partial + LND & $\mathrm{CT}+$ aromatase & Ductal carcinoma & $(+)$ & $(+)$ & $(-)$ & $3 / 13$ & * & * \\
\hline Diniz [2] & 2012 & 82 & 2 & Partial & RT + letrozole & IDC & $(+)$ & $(+)$ & * & * & DF & 48 \\
\hline McMaster [31] & 2013 & 60 & 3 & Partial & RT & Ductal carcinoma & $(+)$ & * & $*$ & * & $*$ & $*$ \\
\hline Bogani [9] & 2013 & 71 & 4 & Vulvectomy + SLNB—LND & $\mathrm{CT}+$ tamoxifen & Ductal carcinoma & $(+)$ & $(+)$ & * & $1 / 8$ & DF & 24 \\
\hline Lamb [5] & 2013 & 59 & 1 & Partial + LND & Tamoxifen & Adenocarcinoma & $(+)$ & $(+)$ & $(-)$ & * & $*$ & $*$ \\
\hline James [7] & 2015 & 62 & 1.3 & Partial & $\mathrm{CT}+\mathrm{RT}$ & IDC & $(+)$ & $(+)$ & $(-)$ & * & $\operatorname{Rec}$ & 13 \\
\hline Present case & 2016 & 72 & 1.5 & Partial + SLNB & Aromatase & IDC & $(+)$ & $(+)$ & $(-)$ & $0 / 1$ & DF & 6 \\
\hline
\end{tabular}

LND (inguinal)lymph node dissection, LND1 (inguinal and pelvic) LND, SLNB sentinel lymph node biopsy, CT chemotherapy, RT radiotherapy, ILC invasive lobular carcinoma, IDC invasive ductal carcinoma, Dead death of disease, DF disease-free, Rec recurrence, ${ }^{*}$ unknown 
metastasis from primary orthotopic breast carcinoma or adenocarcinoma of other organs.

Sentinel node mapping in vulva cancer is a more contemporary topic in the literature [7]. An observational study followed 403 patients with primary vulvar cancer of less than $4 \mathrm{~cm}$ that had been treated with sentinel node mapping. In 276 patients with vulvar disease and a negative sentinel node (median follow-up time, 35 months), eight inguinal recurrences were diagnosed (3.0\%). The inguinal recurrence rate was low; therefore, it was suggested that sentinel node dissection, performed by a qualitycontrolled multidisciplinary team, should be part of the standard treatment in selected patients with early-stage vulvar cancer [8]. In most cases, surgical methods for primary ectopic breast cancer of the vulva included surgical excision with inguinal lymph node dissection. One published study utilized sentinel lymph node biopsy for recurrent case after a previous lymph node dissection [7]. Two studies reported the use of SLNB for non-recurrent cases followed by complete ipsilateral inguinal lymph node dissection $[9,10]$. Our case is the first reported case of only SLNB for non-recurrent primary breast cancer of the vulva. We identified the sentinel lymph node in ipsilateral inguinal lymph nodes as effectively as other reports in which isotope or dye used.

We suppose that pelvic node resection following inguinal lymph node resection is necessary if the sentinel node is found to be positive for ectopic breast cancer of the vulva because, in our case, lymphoscintigraphy showed a hot area in a right obturator lymph node. In a randomized, controlled trial that followed 114 patients with vulvar cancer with groin node metastasis allocated to postoperative pelvic and groin radiation or to ipsilateral pelvic node resection after radical vulvectomy and inguinal lymphadenectomy, long-term follow-up confirmed a significant recurrence-free and cancer-related death benefit of radiation compared with pelvic node resection [11]. In the case of the primary ectopic breast cancer of the vulva, pelvic node resection and/or pelvic and groin radiation should (after ipsilateral inguinal lymph node dissection) be considered if the inguinal lymph node is positive.

Due to the rarity of this diagnosis, there are no established guidelines for postoperative treatment. Virtually all of the literature consists of individual case reports, and most authors recommend appropriate treatment for primary orthotopic breast cancer of a similar stage. Therefore, treatment should consist of an individualized combination of surgery, chemotherapy, trastuzumab therapy, radiotherapy, and hormonal therapy [4].

\section{Conclusions}

Ectopic primary breast cancer of the vulva is an extremely rare condition, and diagnosis is made based on the pathology as well as exclusion of orthotopic breast cancer. Due to the rarity of this diagnosis, there are no established guidelines for the treatment of the patient. The appropriate treatment for a primary orthotopic breast cancer of a similar stage is recommended. Our patient was treated with local excision of the vulva and SLNB and adjuvant hormonal therapy with an aromatase inhibitor. We consider SLNB to be an effective alternative to inguinal node dissection for ectopic primary breast cancer of the vulva.

\section{Abbreviations}

GCDFP-15: Gross cystic disease fluid protein 15; ICG: Indocyanine green; SLNB: Sentinel lymph node biopsy

\section{Authors' contributions}

$T \mathrm{~T}, \mathrm{YT}$, and $\mathrm{HT}$ conducted these operations and drafted the manuscript. RN, $\mathrm{RK}, \mathrm{Yl}, \mathrm{MK}, \mathrm{HN}$, and HS helped to draft the manuscript. All authors read and approved the final manuscript.

\section{Competing interests}

The authors declare that they have no competing interests.

\section{Consent for publication}

Written informed consent was obtained from the patient for the publication of this case report and any accompanying images.

\section{Ethics approval and consent to participate}

The planned therapy was examined and approved in advance in the institutional breast cancer review board, and written informed consent of performing the operation was obtained from the patient along with the family.

\section{Publisher's Note}

Springer Nature remains neutral with regard to jurisdictional claims in published maps and institutional affiliations.

Received: 15 February 2017 Accepted: 5 May 2017

Published online: 16 May 2017

\section{References}

1. Fracchioli S, Puopolo M, De La Longrais IA, Scozzafava M, Bogliatto F, Arisio R, Micheletti L, Katsaros D. Primary "breastlike" cancer of the vulva: a case report and critical review of the literature. Int J Gynecol Cancer. 2006; 16(Suppl1):423-8.

2. Diniz C. Primary breast cancer of the vulva: a case report. J Low Genit Tract Dis. 2012;16(2):155-7.

3. Dmitry V. Lesions of anogenital mammary-like glands: an update. Adv Anat Pathol. 2011;18:1-28

4. North J. Primary breast cancer of the vulva: case report and literature review. Aust N Z Obstet Gynaecol. 2007;47:77-9.

5. Lamb A, Darus CJ, Skripenova S, Weisberg T, Miesfeldt S. Association of primary breast cancer of the vulva with hereditary breast and ovarian cancer. J Clin Oncol. 2013;31(13):231-2.

6. Wick MR. Gross cystic disease fluid protein-15 as a maker for breast cancer: immunohistochemical analysis of 690 human neoplasms and comparison with alpha-lactalbumin. Hum Pathol. 1989;20:281-7.

7. James C, Ramez E, Krishnansu T. Sentinel lymph node mapping of a breast cancer of the vulva: case report and literature review. World J Clin Oncol. 2015;6(2):16-21.

8. Van der Zee AGJ, Oonk MH, De Hullu JA, Anca C. Sentinel node dissection is safe in the treatment of early-stage vulvar cancer. J Clin Oncol. 2008;26:884-9.

9. Bogani G, Uccella S, Cromi A, Casarin J, Donadello N, Ghezzi F. Primary mammary-like ductal carcinoma of the vulva: a case report and analysis of the literature. Am J Dermatopathol. 2013;35(6):685-7.

10. Martinez-Palones JM, Perez-Benavente A, Diaz-Feijoo B, Gil-Moreno A, Roca I, García-Jimenez A, Aguilar-Martinez I, Xercavins J. Sentinel lymph node identification in a primary ductal carcinoma arising in the vulva. Int J Gynecol Cancer. 2007;17(2):471-7. 
11. Kunos C, Simpkins F, Gibbons H, Tian C, Homesley H. Radiation therapy compared with pelvic node resection for node-positive vulvar cancer. Am Coll Obstetricians Gynecologists. 2009;114(3):537-46.

12. Greene HJ. Adenocarcinoma of supernumerary breasts of the labia majora in a case of epidermoid carcinoma of the vulva. Am J Obstet Gynecol. 1935;31:660-3.

13. Hendrix RC, Behrman SJ. Adenocarcinoma arising in a supernumerary mammary gland in the vulva. Obstet Gynecol. 1956;8:238-41.

14. Guerry RL, Pratt-Thomas HR. Carcinoma of supernumerary breast vulva with bilateral mammary cancer. Cancer. 1976;38:2570-4.

15. Cho D, Buscema J, Rosenshein N, Woodruff D. Primary breast cancer of the vulva. Obstet Gynecol. 1985;66:79S.

16. Simon KE, Dutcher JP, Runowitz CD, Wiernik PH. Adenocarcinoma arising in vulvar breast tissue. Cancer. 1998;62:2234-8.

17. Rose PG, Roman LD, Reale FR, Tak WK, Hunter RE. Primary adenocarcinoma of the breast arising in the vulva. Obstet Gynecol. 1990;76:537-9.

18. Di Bonito L, Patriarca S, Falconieri G. Aggressive "breast-like" adenocarcinoma of vulva. Pathol Res Pract. 1992;188:211-4

19. Bailey CL, Sankey HZ, Donovan JT, Beith KA, Otis CN, Powell JL. Primary breast cancer of the vulva. Gynecol Oncol. 1993;50:379-83.

20. Levin M, Pakaras RM, Chang HA, Maiman M, Goldberg SL. Primary breast carcinoma of the vulva: a case report and review of the literature. Gynecol Oncol. 1995;56:448-51

21. Kennedy DA, Hermina MS, Xanos ET, Schink JC, Hafez GR. Infiltrating ductal carcinoma of the vulva. Pathol Res Pract. 1997;193:723.

22. Irvin WP, Cathro HP, Grosh WW, Rice LW, Andersen WA. Primary breast carcinoma of the vulva: a case report and literature review. Gynecol Oncol. 1999;73:155.

23. Gorisek B, Zegura B, Kalavar R, But I, Krajnc I. Primary breast cancer of the vulva: a case report and review of literature. Wien Klin Wochenschr. 2000;112:855.

24. Neumann I, Strass HG, Buchmann J, Koelbl H. Ectopic lobular breast cancer of the vulva. Anticancer Res. 2000;20:4805-8.

25. Piura B, Gemer O, Rabinovich A, Yanai-Inbar I. Primary breast carcinoma of the vulva: case report and review of literature. Eur J Gynaecol Oncol. 2002;23:21-4.

26. Chung-Park M, Liu CZ, Giampoli EJ, Emery JD, Shalodi A. Mucinous adenocarcinoma of ectopic breast tissue of the vulva. Arch Pathol Lab Med. 2002;126:1216-8

27. Yin C, Chapman J, Tawfik O. Invasive mucinous (colloid) adenocarcinoma of ectopic breast tissue in the vulva: a case report. Breast J. 2003;9:113-5.

28. Lopes G, DeCesare T, Ghurani G, Vincek V, Jorda M, Glück S, Silva O. Primary ectopic breast cancer presenting as a vulvar mass. Clin Breast Cancer. 2006; 7:278-9.

29. Fracchioli S, Puopolo M, De La Longrais IA, Scozzafava M, Bogliatto F, Arisio R, Micheletti L, Katsaros D. Primary "breastlike" cancer of the vulva: a case report and critical review of the literature. Int I Gynecol Cancer. 2006;16:423-8.

30. Naseer MA, Mohammed SS, George SM, Das Majumdar SK. Primary ectopic breast cancer mimicking as vulval malignancy. J Obstet Gynaecol. 2011:31:553-4.

31. McMaster J, Dua A, Dowdy SC. Primary breast adenocarcinoma in ectopic breast tissue in the vulva. Case Rep Obstet Gynecol. 2013;2013:721696.

\section{Submit your manuscript to a SpringerOpen ${ }^{\circ}$ journal and benefit from:}

- Convenient online submission

- Rigorous peer review

- Immediate publication on acceptance

- Open access: articles freely available online

- High visibility within the field

Retaining the copyright to your article 